\title{
Complicated High-Rise Structure Design of NingBo-Liansheng Commercial Plaza
}

\author{
Sufen Shi*
}

Institude of Ningbo Urban Construction Design and Research, Zhejiang, China, 315000

\begin{abstract}
NingBo-Liansheng International Commercial Plaza is a twin towers with high-connection. It is a complex tall building. The frame-shear wall structure system is used. The connection body is in 21 and 22 layers. The connection system is strong connection and the two storey steel trusses are used. The north and South towers are placed by certain angle, and it designed for the adjustment of plane with layout of shear wall near two tower dynamic characteristics. For the complexity of connection system, the performance of different design goals are worked out for connecting different parts of body as well as the tower. According to the calculation results and to take measures to strengthen the connection body, the connection system can achieve the design target. It ensures the safety and reliability of the whole structure.
\end{abstract}

Keywords: Strong connection structure, the performance design objective, twin towers.

\section{INTRODUCTION}

Located in Ningbo Yinzhou Central District, NingBoLiansheng International Commercial Plaza is divided into two phases for development, of which B1 phase is four floors of shops, B2 phase is high-rise buildings with 62322 square meters construction area and 22 layers, divided into north and south towers. The north and south towers above 21 layers are connected into a whole through a connection body, forming an interoperability structure, mainly for apartments and commercial buildings. The basement is of 2 layers, mainly for parking lots, equipments rooms and subsidiary rooms. Due to the ordered of development time, settlement nodes are adopted to disconnect the main buildings and podium buildings. Please see Fig. (1) for architectural renderings.

The safety classes of building structures of this project is Class II, the designed service life is 50 years [1,2]. Class for earthquake resistance of buildings is Class $\mathrm{C}$. The designations of Groundsill basis and pile foundation are both Class A. According to the results of engineering geological drilling, thickness of covering layers is less than $80 \mathrm{~m}$, according to Seismic Safety Evaluation Report of NingBo-Liansheng Commercial Plaza, equivalent shear wave velocity of planned worksites is $139 \mathrm{~m} / \mathrm{s}$, and the classification of worksites is Class III [1]. The project has been completed and accepted by the end of 2010 .

B2 1 5 layers are podiums, parts above the podiums are divided into north and south towers, a 15-degree angle lays up between towers with a distance of $16 \sim 29 \mathrm{~m}$, please see construction plan 2 and Fig. (3) for details.
For the need of elevation, the east and the west sides of north and south towers form out-extended and adduction structure with irregular vertical space, 21 layers above are provided with two connections system to connect the north and south towers. It is a twin-tower complex high-rise building $[3,4]$.

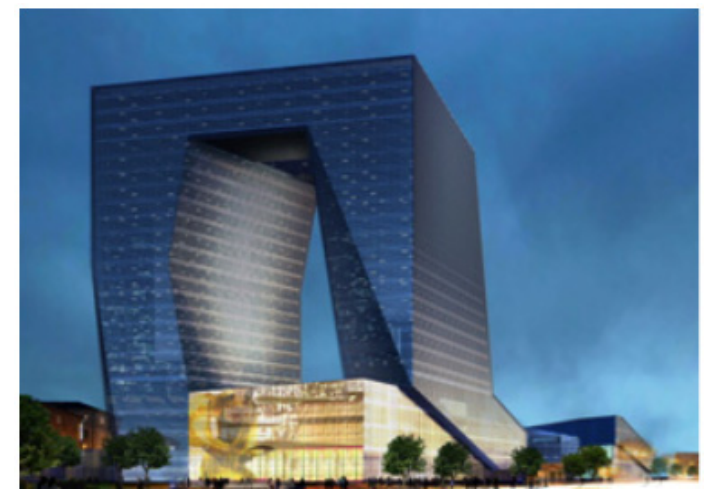

Fig. (1). Impression drawing.

\section{ARCHITECTURE SUMMARY}

The frame-shear wall structure and cast-in-place floor system is used in this project, which adopts liftway and stairway walls to arrange as cylindrical shear walls [5-6]. The typical floor of main buildings is 3.6 meters in storey height. The size of main column grids is $8.40 \mathrm{~m} * 8.40 \mathrm{~m}$. The connecting body part is provided with six steel trusses to connect the towers, with truss height of $10.2 \mathrm{~m}$, two storey heights. Through embedded steel shapes in steel truss support (frame column), it achieves the rigid connection between connection body and towers [7-9]. Grade III is set for seismic shear walls, and the seismic grade for the frame is Grade III [10-11]. The seismic grade between the connection body and its adjacent frames, shear walls is Grade II. 

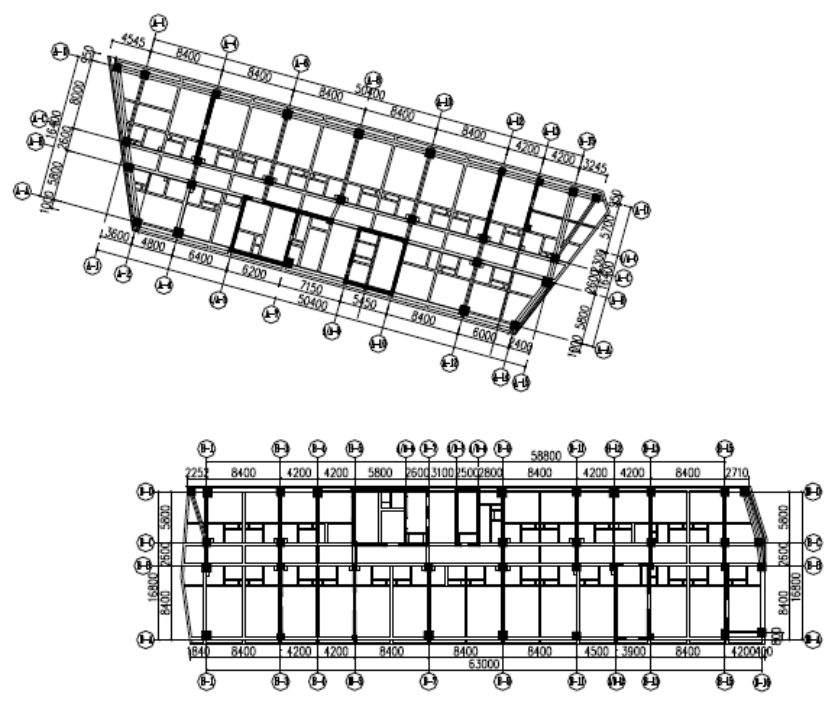

Fig. (2). Structural plan of twelve layers.

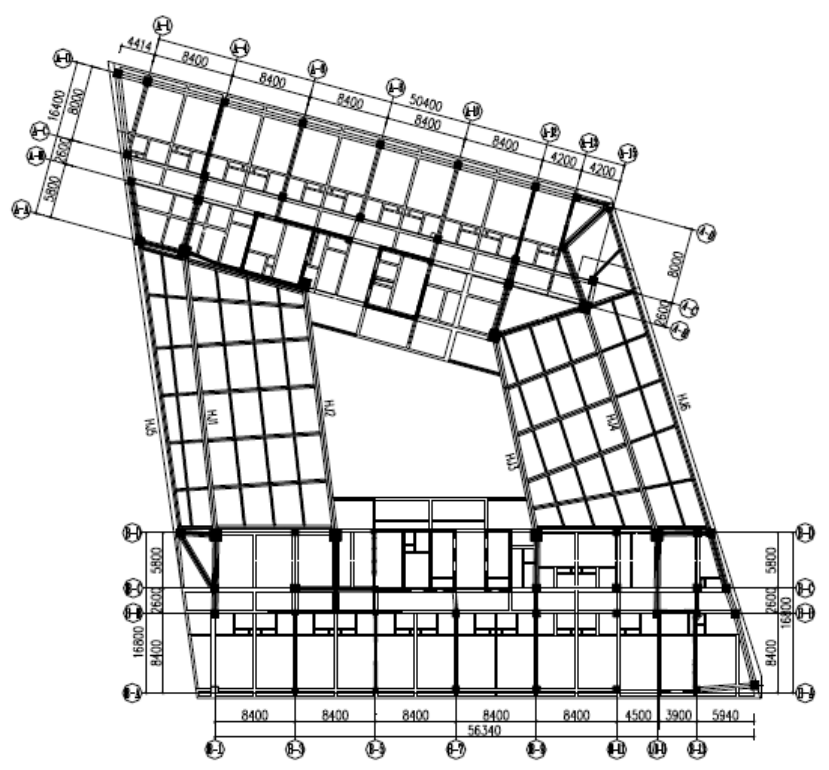

Fig. (3). Structural plan of twenty-one layers.

\section{STRUCTURE DESIGN}

\subsection{Basic Design}

The basement in this project has 2 layers, bored piles are adopted, the combined layers of 8-2 layer (sand layer) and 83 layer (gravelly sand layer) are used as bearing layers for piles, with an effective pile length of $57 \mathrm{~m}$, and pile toe enters into bearing layers for $1 \mathrm{~m}$ above. According to the different loads in tower high-rise buildings and podiums columns, $\Phi 700$ bored piles with bearing capacity characteristic value of $\mathrm{Ra}=3100 \mathrm{kN}$ are adopted under the columns, $\Phi 800$ bored piles with bearing capacity characteristic value of $\mathrm{Ra}=4100 \mathrm{kN}$ are adopted under towers, and the strength grades of concrete on pile body are both $\mathrm{C} 35$.

Raft foundation is used under north and south towers, with a raft thickness of $1.9 \mathrm{~m}$. $1.5 \mathrm{~m}$ thick raft foundation is adopted under podiums between towers for transition, for the purpose of reducing the differential settlement of single body at the two sides of the connection body and strengthening reinforcement. The later construction settlement shows that, the settlement is $23 \mathrm{~mm}$ in South Tower and $21 \mathrm{~mm}$ in North Tower, basically the same settlement on both sides, effectively reducing the additional stress caused by differential settlement in connection body.

\subsection{Topside Structure Design}

East and west connection bodies are respectively provided in 21 layer and 22 layer of the buildings, east connection body is $24.0 \mathrm{~m}$ in length and $17.2 \mathrm{~m}$ in width, while the west connection body is $26.0 \mathrm{~m}$ in length and $17.0 \mathrm{~m}$ in width, 32 -storey steel trusses with storey height of $5.1 \mathrm{~m}$ are respectively provided in each connection body as main stress components, the total height of steel truss is $10.2 \mathrm{~m}$. The thickness of lower middle floor slabs of connecting body is 200 . Thickness of upper floor slabs is 150 , made up by steel bar truss concrete.

As the existence of connection bodies, it should first determine whether weakly or strongly connected structure is adopted between connection body and tower. If weak ties are adopted, each tower has clear stress and minimum mutual influence between towers, connection body is simply laid up, but the relative displacement between towers under the actions of horizontal earthquake and wind load should be accurately calculated, or corridors will collide or fall as hinged support loses its efficacy caused by major earthquake. Characteristics of connection bodies in the project should be carefully considered, plan view size of the two connection bodies is relatively large, including three floor systems and respectively 32 -storey steel trusses for connecting towers. The connection bodies have enough strong stiffness and relatively thick floor slab in each layer to connect north and south towers as a whole for stress and deformation coordination. And simple support with larger size, which will affect the elevation modeling, is not allowed in buildings. So the strong ties are determined to be the connecting format between connection bodies and towers.

It requires each single tower in twin-tower connected structure should have a similar shape, plane layout and stiffness in JGJ 3-2010. Before the overall analysis, it determines plane layout of shear wall structure for two towers with the goal of stiffness, vibration mode and period approach, as shown in Figs. (2 and $\mathbf{3}$ ).

\subsection{Structural Calculation of Single Tower}

The project adopts SATWE (2005 Edition) and PMSAP for calculation and ETABS for result checking. The intensity of an earthquake resistance of buildings is 6 , the designed basic earthquake acceleration value is $0.05 \mathrm{~g}$, the designed earthquake group is the first group, the maximum horizontal seismic coefficient is 0.04 , the characteristic period of soil layer is $0.45 \mathrm{~s}$, the damping ratio is 0.05 . Seismic force calculated by Equ. (1).

$$
\begin{aligned}
& F_{x j i}=\alpha_{j} \gamma_{t j} X_{j i} G_{i} \\
& F_{y j i}=\alpha_{j} \gamma_{t j} Y_{j i} G_{i} \\
& i=1,2 \cdots, n, \quad j=1,2 \cdots, m
\end{aligned}
$$


The fundamental wind pressure is $0.6 \mathrm{Kn} / \mathrm{m} 2(100$ years of recurrence interval), the surface roughness is Class B, and the wind-induced vibration coefficient is 1.8 according to Wind Load CFD Numerical Calculation Report of NingBoLiansheng Commercial Plaza. The calculating wind load is shown in Equ.(2).

$\omega_{k}=\beta_{z} \mu_{z} \mu_{s} \omega_{0}$

Where, the $\omega_{k}$ is Standard values of wind load, the $\omega_{0}$ is basic wind pressure, the $\mu_{z}$ is height variation coefficient of wind pressure, the $\mu_{s}$ is wind load factor, and the $\beta_{z}$ is wind vibration coefficient of $Z$.

Because of the requirements of architectural plane and function setting, north and south towers combine with liftway and stairway to form a core tube, but the barrel is bias, shear walls are arranged in room separator lines expect the barrel, to strengthen torsional stiffness and to make similar stiffness, basically the same vibration mode direction between towers. Please refer to Table 1, Table 2 for first threeorder vibration mode of structural analysis of north and the south towers.

(1) South Tower

Table 1. Natural vibration period (period 1 for SATWE, period 2 for ETABS).

\begin{tabular}{|c|c|c|c|}
\hline $\begin{array}{c}\text { Vibration } \\
\text { Mode }\end{array}$ & Period 1 & $\begin{array}{c}\text { Translation } \\
\text { Coefficient }\end{array}$ & Period 2 \\
\hline \hline $\mathrm{T} 1$ & 2.2322 & $0.86(\mathrm{Y})$ & 2.1114 \\
\hline $\mathrm{T} 2$ & 2.0583 & $0.89(\mathrm{X})$ & 1.8610 \\
\hline $\mathrm{T} 3$ & 1.7827 & 0.25 (Torsion) & 1.6306 \\
\hline
\end{tabular}

In the South Tower, the ratio of the first natural vibration period T3 with torsion as the principal coefficient and the first natural vibration period $\mathrm{T} 1$ with translation as the principal coefficient is 0.80 , less than 0.85 , in accordance with the design specifications.

(2) North Tower:

Table 2. Natural vibration period. (period 1 for SATWE, period 2 for ETABS).

\begin{tabular}{|c|c|c|c|}
\hline $\begin{array}{c}\text { Vibration } \\
\text { Mode }\end{array}$ & Period 1 & $\begin{array}{c}\text { Translation } \\
\text { Coefficient }\end{array}$ & Period 2 \\
\hline \hline $\mathrm{T} 1$ & 2.4022 & $0.98(\mathrm{Y})$ & 2.2525 \\
\hline $\mathrm{T} 2$ & 2.1736 & $0.72(\mathrm{X})$ & 2.0230 \\
\hline $\mathrm{T} 3$ & 1.8269 & 0.30 (Torsion) & 1.6592 \\
\hline
\end{tabular}

In the North Tower, the ratio of the first natural vibration period $\mathrm{T} 3$ with torsion as the principal coefficient and the first natural vibration period $\mathrm{T} 1$ with translation as the principal coefficient is 0.76 , less than 0.85 , in accordance with the design specifications.

As it is a twin-tower connected structure, in the calculation, the period ratio, displacement ratio of single tower and bearing earthquake overthrow moment of shear walls should be first controlled. After the calculation (three software, SATWE, PMSAP, ETABS are adopted for verification), the ratios of the first torsion period and the first translation period of single tower are both less than 0.8 ; the ratio of the displacement meeting the maximum storey horizontal displacement and inter-story displacement in accidental eccentricity under earthquake action and the average value is less than 1.4, and the maximum displacement angle meets the requirements of normative complicated tall buildings. The structure seismic overturning moment of shear walls exceeds $50 \%$ of the total structure seismic overturning moment.

From the first 3-order vibration mode, north and south towers have approximate periods, vibration modes in period 1 are both of Y direction, which explains that they have the similar stiffness, both getting weak in Y direction. The direction angle of the first vibration mode in South Tower is 111.97 degrees, and it is 121.50 degrees for the direction angle of the first vibration mode in South Tower (converted into the same coordinate system), which are basically approximate. This explains that the shear walls are reasonably arranged, which has reached the expected target of structure arrangement, so that torsion will not be generated in overall model due to significant differences in the direction of the first vibration mode of two towers.

\subsection{Overall Structure Calculation}

In the overall model, the ratio of the first natural vibration period $\mathrm{T} 4$ with torsion as the principal coefficient and the first natural vibration period $\mathrm{T} 1$ with translation as the principal coefficient is 0.30 , less than 0.85 , in accordance with the design specifications.

After the overall calculation, the ratio of the first tensional period and the first translation period is less than or equal to 0.85 ; the ratio of the displacement meeting the maximum storey horizontal displacement and inter-story displacement in accidental eccentricity under earthquake action and the average value is less than 1.4 , and the maximum displacement angle meets the requirements of normative complicated tall buildings. The calculation results show that, two three-layer connection bodies node two towers, the connection bodies have enough strong stiffness and deformation coordination, under eccentric loading, torsion appears in the fourth period, the ratio of the maximum displacements is less than 1.2. Particularly when $Y$ direction get its maximum displacement angle, $\mathrm{Y}$ directional displacement angle is much larger than the $\mathrm{X}$ directional displacement angle in a single tower, which shows that two directions have significantly different stiffness, as a whole, the $\mathrm{Y}$ directional stiffness is strengthened, the maximum displacement angle in $\mathrm{X}$ direction (1/8679) and the maximum displacement angle in Y direction (1/6519) are relatively close in overall calculation, this is enough to illustrate that the overall stiffness in two directions are similar, when torsional stiffness is strengthened, torsion period will appear in higher modes.

\subsection{Structural Dynamic Time History Analysis}

Elastic time history analysis of PMSAP and ETABS is adopted in this project for structural calculation. Based on the elastic time history analysis on 6 degree earthquake and 
Class III worksite, the maximum earthquake acceleration value is $18 \mathrm{~cm} / \mathrm{s} 2$, the time interval is $0.02 \mathrm{~s}$, and the damping ratio is 0.05. PMSAP inputs two natural waves (TH3TG045, TH4TG045) and an artificial wave (RH2TG045); ETABS inputs two natural waves (Tianjin TJ, Tangshan TS) and an artificial wave (Shanghai RG). The calculation results of PMSAP and ETABS are as shown in Table 3 and Table 4.

Table 3. Natural vibration period. (period 1 for SATWE, period 2 for ETABS).

\begin{tabular}{|c|c|c|c|}
\hline $\begin{array}{c}\text { Vibration } \\
\text { Mode }\end{array}$ & Period 1 & $\begin{array}{c}\text { Translation } \\
\text { Coefficient }\end{array}$ & Period 2 \\
\hline \hline $\mathrm{T} 1$ & 2.3121 & $0.90(\mathrm{Y})$ & 2.1114 \\
\hline $\mathrm{T} 2$ & 2.1235 & $0.85(\mathrm{X})$ & 1.8610 \\
\hline $\mathrm{T} 3$ & 2.0764 & $0.61(\mathrm{X})$ & 1.6306 \\
\hline $\mathrm{T} 4$ & 0.7049 & 0.59 (Torsion) & \\
\hline
\end{tabular}

Table 4. Base shear and bending moment.

\begin{tabular}{|c|c|c|c|}
\hline \multicolumn{2}{|c|}{ Seismic wave } & Mode-superposition res- & Mean \\
\hline \multirow{2}{*}{$\begin{array}{c}\text { Base } \\
\text { shear }(\mathrm{KN})\end{array}$} & $\mathrm{X}$ & 12415.7 & 14079 \\
\hline & $\mathrm{Y}$ & 13086 & 10705 \\
\hline \multirow{2}{*}{$\begin{array}{c}\text { Basal bending } \\
\text { moment (KN- } \\
\text { M) }\end{array}$} & $\mathrm{X}$ & 683000 & 614000 \\
\hline & Y & 593000 & 539000 \\
\hline
\end{tabular}

(1) Calculation Results of PMSAP

All the structural base shears calculated by seismic waves are greater than $65 \%$ of the ones calculated by modesuperposition response spectrum method, the mean value of structural base shears calculated by seismic waves is greater than $80 \%$ of the one calculated by mode-superposition response spectrum method, meeting the specifications of seismic wave selection.

\section{OVERRUN STRUCTURE AND TO TAKE MEAS- URES TO STRENGTHEN THE CONNECTION BODY}

\subsection{Overrun Structure is Embodied in the Following As- pects}

1) Multiple complex structure with multi-tower and connected structural system.

2) Irregular vertical stiffness: trusses are arranged in layer 24, lateral stiffness in layers 21, 22, 23(standard layer structure, the same as below) is $70 \%$ smaller than the adjacent upper story or $80 \%$ smaller than the mean value of three adjacent upper stories, which is weak floor after being checked by SATWE. The lateral stiffness in layer 7 is $70 \%$ smaller than the adjacent upper story or $80 \%$ smaller than the mean value of three adjacent upper stories, which is weak floor after being checked by ETABS. The shear bearing capacity in layer 23 is $65 \%$ less than the one in its upper story.
The ratio of shear bearing capacity in layer 23 and its upper story is 0.44 in $\mathrm{X}$ direction and 0.16 in Y direction;

$3)$ irregular plane: in considering the earthquake action under the influence of accidental eccentricity, the maximum story horizontal displacement and inter-story displacement are both larger than the average value, 1.2 , belonging to irregular torsion.

\subsection{Key Points for Structure Design}

Based on the review opinions to overrun structure, the design of connection bodies is the key of the structural design, and performance objectives are determined the branches of connection bodies, and measures are taken to strengthen the connection body through targeted calculation.

1) Rigid connection is adopted, and it connects the upper, middle and bottom chord members of trusses with bilateral shear walls or profile steel inside frame column to realize the rigid connection. The connecting body part adopts steel structure to reduce the weight of the structure and construct conveniently. Six two-story steel trusses are used to connect the north and south towers, it adopts welded H-shaped cross section $(750 * 500 * 30 * 35 \mathrm{~mm})$ for upper, middle and lower chord members of four trusses(HJ1 HJ4). In order to strengthen in-plane stability of steel trusses, it adopts welded $\mathrm{H}$-shaped cross section $(500 * 500 * 25 * 25 \mathrm{MM})$ for diagonal bracing, and strong axis is arranged on the plane of steel trusses. On East-West wing, it adopts welded H-shaped cross section $(750 * 350 * 22 * 28 \mathrm{~mm})$ for chord members of two trusses (HJ5, HJ6), uses H-shaped cross section $(350 * 350 *$ $22 * 28 \mathrm{~mm}$ ) for diagonal bracing, and strong axis is arranged on the plane of steel trusses. Please refer to Fig. (4) for elevation of typical truss 1 .

2) Seismic grade of adjacent structural components between connection bodies is boosted to a higher level. Chord members of connection bodies of steel truss stretch into the major structure between floors, forming steel reinforced concrete frame-beams and frame-columns, whose seismic grade is also boosted to a higher level (Level II, according to the frame), in order to ensure that the horizontal thrust and tensile forces of steel trusses can effectively spread to the surrounding frame columns and shear walls.

3) There are built-in structural steels in frame columns of bearing parts of connection bodies, which stretch down to layer two as a transition layer, the seismic grade of these frame columns is boosted to a higher level (Level II, according to the frame). According to the elastic-plasticity static analysis (PUSHOVER), the maximum displacement angle of the structure is $1 / 226$, which meets the limiting value of inter-storey elastic-plastic displacement angle in High regulation (Article 4.6.5). In structure, the axial compression ratio of two columns is less than 0.7 , a transverse reinforcement ratio (no less than $1.5 \%$ ) and the minimum structural reinforcement ratio(no less than $1.2 \%$ ) of all longitudinal reinforcements should be improved to guaranteed adequate ductility and deformation properties.

4) The frames between connection bodies for extended areas in the towers are arranged according to elastic design under intermediate earthquake, two-layer concrete construction under connection bodies is made according to un-yield 


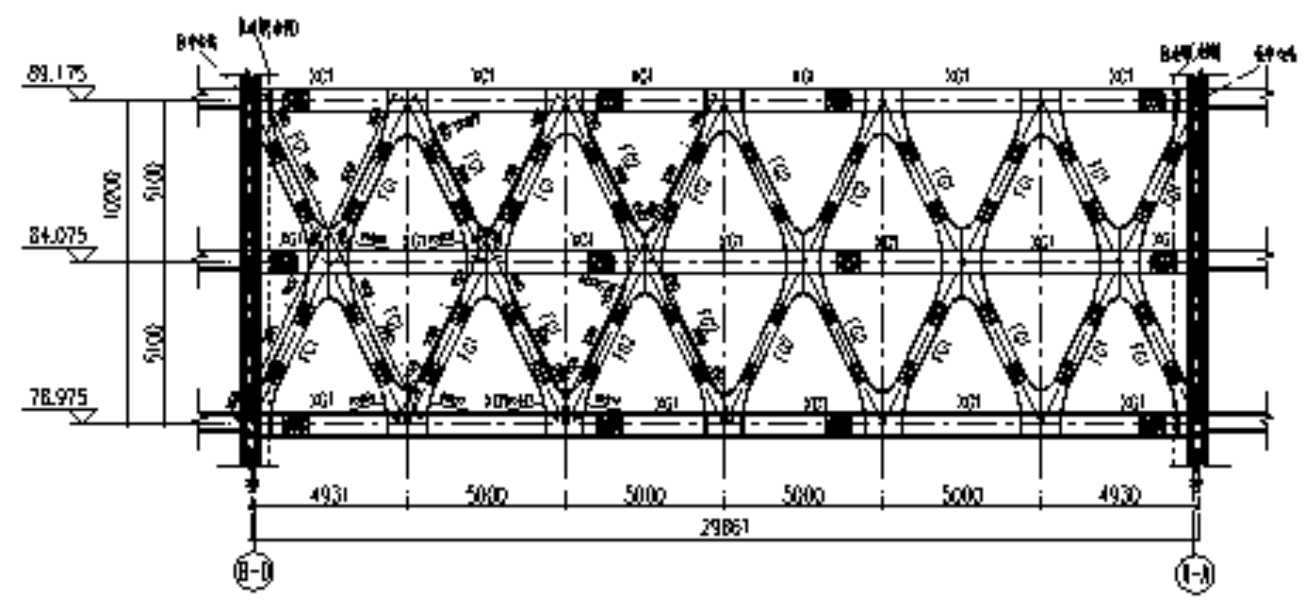

Fig. (4). HJ1 elevation.

design under intermediate earthquake, while the support of connection bodies is designed according to un-yield design under major earthquake. Goals and requirements of different anti-seismic properties are adopted in different parts of connection bodies adopt, effectively achieving the best goal of anti-seismic properties.

5) The overall structure, including connection bodies, uses elastic floors for calculation. Connection bodies adopt steel truss floor, to increase the coordination between towers, ground floor and intermediate layer of connection bodies use $200 \mathrm{~mm}$ thick slabs, while the top layer adopts $150 \mathrm{~mm}$ thick slabs, in addition, the adjacent main body structure is reinforced, slab reinforcements of connection bodies stretch into a span of the adjacent main body. In order to ensure the reliable transmission of floor horizontal force between trusses, the stud is arranged at the junction of the upper surface of chord members and concrete slab, and horizontal support is set between bottom flanges of chord members, which shares the horizontal shears inside the composite slab, so that the stress in the slab can be equally distributed.

6) Post-cast strip is arranged at both ends and midspan of connection bodies of steel trusses, to make full use of the good mechanical properties of steel structure, the stress on concrete floor at both ends and midspan of connection bodies in construction phase is released, and then concrete of post-cast strip is poured after the main structure is completed. Actually, this measure is proved to be reliable and feasible, the floor slab has been keeping in a good state (no crack) since the completion of construction.

7) Restraint flange members are arranged in adjacent shear walls of connection bodies' support, and shear wall reinforcement is strengthened, vertical and horizontal reinforcement ratios reach $0.31 \%$.

8) There is stiffness mutation in the top of podiums and two layers under connection bodies, which is a weak story. In this design, an amplified coefficient of 1.15 is multiplied by a characteristic value of earthquake action, which is appropriately strengthened in structure, for example, thickness of roof of podiums is strengthened to $150 \mathrm{~mm}$, and the relevant reinforcement ratio is increased; reinforcement of frame columns and beams of the two layers under connection bodies is also strengthened.

\subsection{Analysis of Truss Node}

Design of truss node is particularly important. In order to satisfy the node design principles in seismic code of "strong connection-weak bar", ANSYS is adopted to analyze solid modeling for typical nodes to ensure the safety. 1 2 typical nodes are selected for analysis in each truss, combination of earthquake excitations under major earthquake is taken as internal forces in member bars, nodes of steel trusses are required to be unyielding under major earthquake. A total of 8 nodes were analyzed. Taking nodes in lower chord support of $\mathrm{HJ} 1$ as an example, the thickness of the original member bar of node was 35 , under rare earthquake, stresses concentrated in the junction of flange and column under chord members, the maximal stress reached $619 \mathrm{~N} / \mathrm{mm} 2$, far more than the yield strength of steel (Q345B steel), as shown in Fig. (5). In order to improve the mechanical condition of nodal region and strengthen the rigid zone, besides adding the thickness of plates in column node and chord bracket to $45 \mathrm{~mm}$, a piece of diagonal stiffening plate was added for adjustment, and then stress is evenly distributed, the maximum stress decreased significantly, the maximum stress in this region is $259 \mathrm{~N} / \mathrm{mm} 2$, less than yield strength under major earthquake, as shown in Fig. (6).

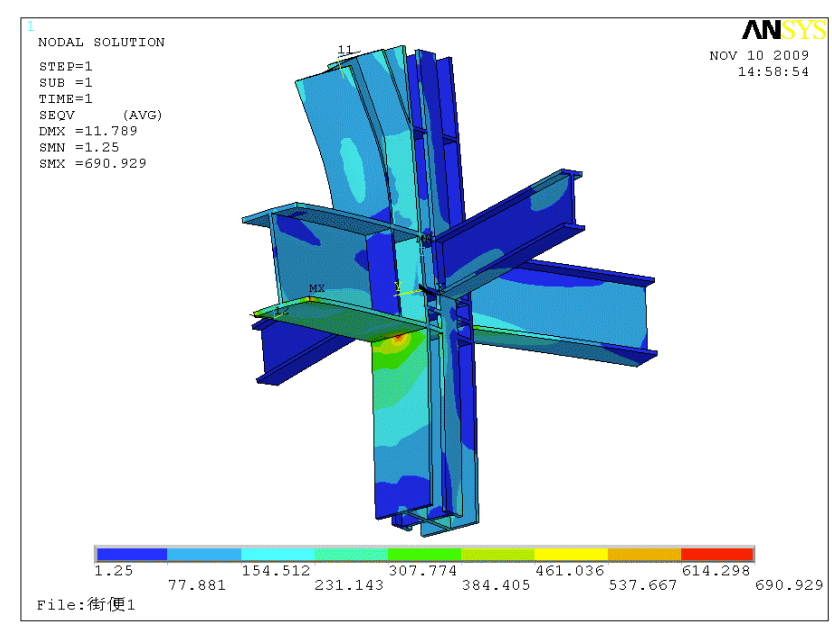

Fig. (5). Structure plane of layer twelve. 


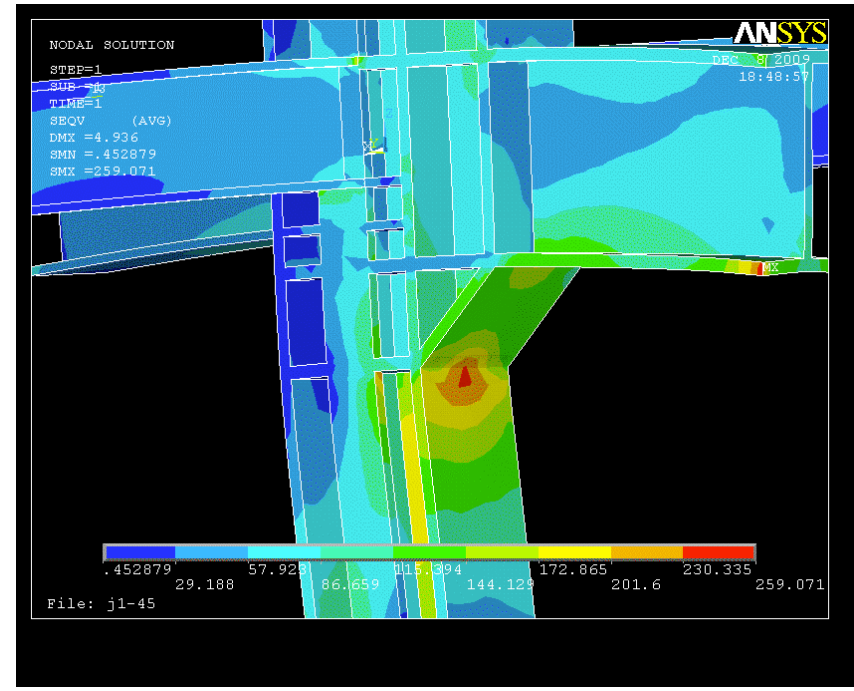

Fig. (6). Structure plane of layer twelve.

To facilitate the construction, cantilevers of web members and chord members between truss supports are welded to column units in factory in advance, in order to ensure the quality of the welding seam. Most of nodes of web members and chord members are spliced with cantilevers on columns on the scene, flanges at top and bottom of chord members adopted complete penetration groove weld for connection, chord web and web members adopted bolts for strong connection.

\section{CONCLUSION}

1) Structured objective is set, the north and the south towers is analyzed and the plane layout of shear walls is confirmed, the dynamic characteristics of two towers are close, and period, direction of vibration mode are close, each tower meets controlling indexes of various parameters in High Regulation, which enables the strong connection between connection bodies to be possible.

2) According to the characteristics of this project, connection bodies have larger size, sufficient stiffness transfers horizontal forces between towers, according to contribution of connection bodies to the main towers, it is determined to be strong connection, to coordinate the common deformation between towers. After the structure of main buildings at the two ends of connection bodies is reliably connected, the overall stress and structural stiffness are more symmetrically distributed, torsional effect under earthquake action is greatly reduced, and both the anti-seismic property and the wind-resistant performance of structure are improved.

3) Based on the node analysis, the construction in truss support is reinforced, seismic grade and sizes of components, including beams, plates and columns of main towers at two sides of connection bodies, are improved, to prevent that them from being damaged under the moderate or strong earthquakes due to stress concentration.

\section{CONFLICT OF INTEREST}

The authors confirm that this article content has no conflict of interest.

\section{ACKNOWLEDGEMENTS}

Declared none.

\section{REFERENCES}

[1] G. Li, "Technical Specification for Concrete Structures of Tall Building (JGJ-2010)," Beijing: Chinese Construction Industry Publishing House, 2010.

[2] P. Xu, "A Complex Structural Design of Tall Buildings," Beijing: Chinese Architecture Industry Press, 2005.

[3] L.H. Han, W. Li, and Y.F. Yang, "Seismic behavior of concretefilled steel tubular frame to RC shear wall high-rise mixed structures," Journal of Constructional Steel Research, vol.65, no.5, pp. 1249-1260, 2009.

[4] A. Farshidianfar, and S. Soheili, "Ant colony optimization of tuned mass dampers for earthquake oscillations of high-rise structures including soil-structure interaction," Soil Dynamics and Earthquake Engineering, vol. 51, pp.14-22, 2013.

[5] X. Zhou, and G. Li, "A macro-element based practical model for seismic analysis of steel-concrete composite high-rise buildings," Engineering Structures, vol. 49, pp. 91-103, 2013

[6] Y. S. Cho, J. H. Kim, S. Uk Hong, and Y. Kim, "LCA application in the optimum design of high rise steel structures," Renewable and Sustainable Energy Reviews, vol. 16, no. 5, pp. 3146-3153, 2012.

[7] S. I. Lee, J. S. Bae, and Y. S. Cho, "Efficiency analysis of Setbased Design with structural building information modeling (SBIM) on high-rise building structures," Automation in Construction, vol. 23, pp. 20-32, 2012.

[8] D. Zou, T. Liu, J. Teng, C. Du, and B. Li, "Influence of creep and drying shrinkage of reinforced concrete shear walls on the axial shortening of high-rise buildings," Construction and Building Materials, vol. 55, pp. 46-56, 2014.

[9] J. Tamošaitienè, E. Gaudutis, and M. Kračka, "Integrated Model for Assessment of High-Rise Building Locations," Procedia Engineering, vol. 57, pp. 1151-1155, 2013.

[10] O. Hasançebi, T. Bahçecioğlu, Ö. Kurç, and M.P. Saka, “Optimum design of high-rise steel buildings using an evolution strategy integrated parallel algorithm," Computers \& Structures, vol. 89, no. 21-22, pp. 2037-2051, 2011.

[11] B. S. Smith, and D.P. Abergel, "Approximate analysis of high-rise structures comprising coupled walls and shear walls," Building and Environment, vol. 18, no. 1-2, pp. 91-96, 1983. 